\title{
LA REGULACIÓN DE LAS PARADAS POLICIALES: UNA COMPARATIVA INTERNACIONAL ${ }^{1}$
}

\author{
José María López-Riba \\ Universidad Pompeu Fabra \\ Josemaria.lopez@upf.edu
}

Sumario: 1. Introducción: paradas policiales. 2. El modelo anglosajón: parada y cacheo. 3. El modelo europeo continental: el control de identidad. 4. La regulación de la identificación policial en España. 5. La dificultad de regular y monitorear las paradas policiales. 6. Conclusiones. 7. Referencias.

Resumen: Las paradas policiales son una línea de investigación jurídica y criminológica destacada en muchos países, sobre todo anglosajones, y cada vez más relevante en otros, como en general los países europeos y, en concreto, España. Sin embargo, existe poca literatura comparando la regulación de las mismas. Con la intención de contribuir en este aspecto, el presente artículo describe los dos principales modelos de regulación internacionales de las paradas policiales: el modelo anglosajón de Stop and Search o Stop and Frisk, presente en países como Reino Unido, y el modelo europeo continental de control de identidad, presente en países europeos como Francia y también en países latinoamericanos como Chile. Respecto a este último modelo se hará un análisis más detallado para el caso español. Pese a las diferencias entre modelos de

1 Me gustaría agradecer a la Dra. Elena Larrauri y a Úrsula Ruiz Cabello, así como al resto de miembros del Grupo de Investigación en Criminología y Sistema Penal de la Universidad Pompeu Fabra sus valiosos comentarios en las versiones tempranas de este artículo. Esta investigación ha sido posible gracias a una ayuda para la contratación del personal investigador novel de AGAUR (FI-2016) y a los proyectos «Ejecución y supervisión de la pena: Calidad de la intervención, legitimidad y reincidencia» (Ref. DER2015-64403-P) y «Desarrollo de un modelo criminológico y empírico de la política criminal (EmpiriC)» (Ref. DER2017-90552-REDT) financiados por MINECO. 
regulación se puede observar que comparten una serie de características que en ambos casos dificultan el control legal efectivo de las paradas policiales. Por último, a modo de conclusión, se expondrán las principales similitudes y diferencias entre los dos modelos.

Palabras clave: paradas policiales; identificaciones policiales; stop and search; policía; regulación de potestades policiales.

Abstract: Police stops are a key legal and criminological research topic in many countries especially in the Anglo-Saxon context and it is gaining relevance in others, in general in European countries such as Spain. However, there is little comparative research about the regulation of this police power. With the aim to contribute in this aspect, this article presents the two principal models of regulation of police stops internationally: the Anglo-Saxon model of Stop and Search or Stop and Frisk present in countries like United Kingdom and the European continental model of control of identity present in European countries like France and also in Latin-American countries such as Chile. Regarding this model, Spain will be analyzed in more detail. Despite the differences between the models it can be observed how they share some characteristics and these characteristics make difficult to subject police stops to effective legal control. Finally as a conclusion, the similarities and differences between models will be displayed.

Keywords: police stops; police identity checks; stop and search; policing; regulation of police powers.

\section{Introducción: las paradas policiales}

El concepto «parada policial» hace referencia a diferentes potestades que tiene la policía. Estas pueden variar entre las regulaciones de diferentes países. No obstante, presentan una serie de elementos comunes. De forma genérica, las paradas policiales pueden definirse como aquellas interacciones entre la policía y la ciudadanía, que ocurren a iniciativa de la primera, donde el agente de policía para a una persona en el espacio público o semipúblico y le hace una serie de requerimientos, que van desde pedirle que se identifique a cachearle (BRADFORD, 2017). Ejemplos de parada policial son la identificación policial y la parada y cacheo. La identificación policial, un poder que suelen tener las policías europeas y latinoamericanas, consiste en la parada de una persona en el espacio público o semipúblico seguida del requerimiento de que la persona se identifique. La parada y cacheo, potestad típica de la policía en países anglosajones, es la parada de una persona seguida de un cacheo superficial en búsqueda de objetos prohibidos o utilizados para la comisión de un delito. 
Las paradas policiales son un tema investigación destacado en la literatura internacional, sobre todo en países anglosajones como Reino Unido y Estados Unidos ${ }^{2}$. El estudio de las paradas policiales es relevante principalmente por dos motivos. En primer lugar, llevar a cabo paradas para proceder a identificar o cachear a personas es una de las herramientas principales que utiliza la policía globalmente en su trabajo diario $^{3}$ (BRADFORD y LOADER, 2016; GELMAN, FAGAN y KISS, 2007; OPEN SOCIETY JUSTICE INITIATIVE, 2009; REINER, 2010). Esto implica que frecuentemente las paradas policiales sean la primera ocasión en la que la ciudadanía tenga una interacción con la policía, a iniciativa de esta, en el ejercicio de sus poderes (BOWLING y MARKS, 2015; BOWLING y WEBER, 2011). En segundo lugar, su estudio es relevante porque es una potestad policial intrusiva que afecta a derechos fundamentales como la libertad de movimiento y el derecho a la privacidad ${ }^{4}$ (ASWORTH y ZEDNER, 2014; BOWLING y MARKS, 2015; IRARRÁZABAL, 2015; RÍOS, SEGOVIA y ETXEBARRIA, 2015).

Dado que las paradas policiales son una potestad utilizada rutinariamente y puede afectar a derechos fundamentales deben estar debidamente reguladas. Así parecería necesario prestar atención a cómo se regula esta potestad en diferentes países y así contribuir a la necesaria investigación comparada sobre este tema (BOWLING y MARKS, 2015; BRADFORD y LOADER, 2016).

Por todo ello, este trabajo va dirigido a analizar los dos modelos principales $^{5}$ de regulación de las paradas policiales que aquí se proponen:

2 Ya que en estos países existe una larga tradición en la investigación sobre potestades policiales y estas tienen una gran relevancia pública (ver, por ejemplo, DELSOL y SHINER, 2015; MEARES, 2014; MURRAY y HARKIN, 2017)

3 Por ejemplo, en España en el año 2015 la Guardia Civil y el Cuerpo Nacional de Policía llevaron a cabo 6,5 millones de identificaciones (MINISTERIO DEL INTERIOR, 2016) (Se proporcionan cifras de 2015 puesto que los datos sobre identificaciones no aparecen en los siguientes Anuarios Estadísticos del Ministerio de Interior). Entre 2014 y 2015, en Inglaterra y Gales se llevaron a cabo 540.870 paradas y cacheos (UNITED KINGDOM GOVERNMENT, 2015). En Chile en 2014 se realizaron 1.853.244 controles de identidad (IRARRÁZABAL, 2015).

4 Como así estableció el Tribunal Europeo de Derechos Humanos en el caso Gillan y Quinton v. Reino Unido.

5 Cabe hacer algunas aclaraciones respecto a esta propuesta de los modelos de regulación. Primero, estos modelos son los que el autor ha identificado a partir de una lectura comparada sobre la regulación de las paradas policiales, no obstante no se ha encontrado ningún trabajo que se refiera a estos modelos como tales o que trate otros modelos. En segundo lugar, se proponen estos dos modelos puesto que en las excolonias y, en general, en el Sur global la práctica de las paradas policiales no es tan común y no tiene la misma relevancia (BRADFORD y LOADER, 2016). En tercer lugar, esta clasificación encuentra sentido en que seguramente las diferencias están basadas en las distinciones existentes en estos países entre los sistemas jurídicos Common Law y los de Derecho romano-germánico (DEMICHELE y JANOSKI, 2010) y, sobre todo, entre los sistemas policiales, los modelos británico y norteamericano (fuertemente influenciado por el británico) frente al modelo europeo continental (MAWBY, 2008). Sin embargo, el 
el modelo anglosajón, más explícitamente orientado a la investigación criminal (obtención de pruebas), y el modelo europeo continental, más orientado a las tareas de mantenimiento del orden. Una vez presentados estos modelos se prestará especial atención a la regulación de las identificaciones policiales en España.

\section{El modelo anglosajón: parada y cacheo}

En el modelo anglosajón, presente en países como Reino Unido y Estados Unidos, la parada policial está regulada principalmente como un medio para investigar individuos de los cuales se sospecha que han cometido o van a cometer un delito y, posteriormente, cachearlos si se sospecha que están en posesión de algún objeto ilegal (como drogas o armas) o relacionado con la comisión de una infracción. Una de las características principales de este modelo es el requisito legal de que la parada esté basada en el criterio de sospecha razonable individualizada ${ }^{6}$, un requisito que está desarrollado en la normativa y la jurisprudencia.

En Inglaterra y Gales la sospecha razonable está establecida en el Police and Criminal Evidence Act 1984 (PACE) - Code A que lo define como un test con dos partes:

«i) el agente de policía tiene que tener una sospecha genuina de que encontrará el objeto para el que se habilita la potestad de cachear;

ii) la sospecha de que el objeto será encontrado debe ser razonable. Esto implica que debe haber una base objetiva para esta sospecha fundamentada en hechos, información y/o inteligencia relevante para la probabilidad de que el objeto en cuestión sea encontrado; una base tal que cualquier persona razonable hubiera llegado a la misma conclusión tomando en cuenta los mismos hechos, información y/o inteligencia.» (HOME OFFICE, 2014 p. 5)

En Estados Unidos el requisito de sospecha razonable respecto a las paradas y cacheos está estipulado en la jurisprudencia. En la sentencia del caso Terry v. Ohio se estableció que el requisito se cumplía cuando un agente «es capaz de señalar hechos específicos y articulados, que tomados conjuntamente, junto con inferencias racionales, habilitan la intrusión de forma razonable» (Terry v. Ohio, US SUPREME COURT, 1968).

origen y la extensión de estos dos modelos aquí propuestos debería ser objeto de futuras investigaciones.

6 El Tribunal Europeo de Derechos Humanos definió la sospecha razonable como «la existencia de hechos o información objetiva que satisfarían a un observador imparcial sobre la posibilidad de que la persona en cuestión haya cometido una infracción» (Gusinski v. Russia, TEDH, 2004). 
En Reino Unido no existe homogeneidad normativa sobre esta potestad ya que está regulada en diferentes disposiciones legales. En Inglaterra y Gales las más aplicadas son la sección primera de la Police and Criminal Evidence Act de 1984, que permite el uso de este poder de forma generalizada bajo el requisito de que exista una sospecha razonable de que la persona a la que se interviene posea objetos prohibidos, peligrosos o relacionados con algún delito; la sección 23 de la Misuse of Drugs Act de 1971 y la sección 47 de la Firearms Act de 1968, que también requieren que la parada esté basada en una sospecha razonable de que el individuo porta, en el primer caso, drogas ilegales, o en el segundo caso, armas prohibidas; la sección 60 de la Criminal Justice and Public Order Act de 1994, que permite a un inspector de policía, bajo indicios objetivos de que se van a producir actos violentos, declarar una zona delimitada donde se pueden llevar a cabo paradas y cacheos particulares sin el requisito de sospecha razonable individualizada, por un período de hasta 24 horas; y la sección 163 de la Road Traffic Act de 1988, que permite que un agente de policía pare un vehículo y pueda cachearlo si tiene una sospecha razonable de que el conductor ha cometido o va a cometer un delito.

En Escocia este mismo poder se encuentra regulado en algunas leyes propias. Como las secciones 21, 48(1) y 50 de la Criminal Law Act de 1995 para la búsqueda de objetos no permitidos en eventos deportivos, armas u objetos afilados respectivamente, y la sección 60 (1) de la Civic Government Act de 1982 para la búsqueda de objetos robados. Por otro lado, la policía puede recurrir a esta potestad en base a leyes comunes de Reino Unido, como las anteriormente mencionadas sección 23 de la Misuse of Drugs Act de 1971 y la sección 47 de la Firearms Act de 1968. Las paradas y cacheos que se habilitan en la legislación escocesa deben realizarse cuando exista una sospecha razonable de que la persona porta alguno de los objetos buscados. Como en Inglaterra y Gales, previa autorización de mandos policiales, también existe la habilitación del uso de este poder en una zona delimitada durante un tiempo establecido sin tener una sospecha razonable individualizada sobre una persona particular, en la sección 60 de la la Criminal Justice and Public Order Act de 19947.

Por último, en Irlanda del Norte, de forma similar a Escocia, esta potestad esta gobernada por diferentes legislaciones comunes del Reino Unido y propias. Las más aplicadas son la citada sección 23 Misuse of Drugs Act de 1971 y la sección 3 de la Police and Criminal Evidence (NI) Order 1989 que habilita la parada y el cacheo de personas y vehículos para la búsqueda de objetos robados o prohibidos (en el mismo sentido

7 Uno de los aspectos destacados de la práctica de las paradas policiales en Escocia es que hasta 2013 la mayoría de paradas y cacheos realizados por la policía no se encontraban habilitados por ninguna de estas leyes y se utilizaba el consentimiento de la persona parada para proceder a realizar cacheos, lo que denominaban paradas y cacheos «Voluntarios» (LENNON y MURRAY, 2018; MURRAY, 2014). 
que la Police and Criminal Evidence Act de 1984 de Inglaterra y Gales) (TOPPING y SCHUBOTZ, 2018).

A diferencia de Reino Unido, en Estados Unidos el poder de parar y cachear $^{8}$ (Stop and Frisk) se encuentra habilitado por la jurisprudencia. Concretamente fue autorizado por la sentencia del Tribunal Supremo de 1968 del caso Terry v. Ohio ${ }^{9}$. El Tribunal Supremo estadounidense estableció que la policía podía parar a una persona si existía una sospecha razonable individualizada de que esa persona había cometido un delito, estaba cometiendo un delito o iba a cometerlo en el futuro. Además, si existe una sospecha razonable individualizada, adicional y separada de la anterior, de que la persona porta armas entonces el agente está habilitado para realizar un cacheo superficial. Esta interpretación realizada por el Tribunal Supremo estaba basada en tres principios: individualización, indicios materiales o visuales y especificidad. Sin embargo, la jurisprudencia posterior ha ampliado los supuestos para realizar una parada, como la búsqueda de drogas (Adams v. Williams, US SUPREME COURT, 1972), y ha tendido a flexibilizar los requisitos para llevar a cabo una parada ${ }^{10}$.

En la Tabla 1 se puede observar un resumen de las principales leyes donde está regulada la parada y cacheo en los países anglosajones.

\section{Tabla 1. Resumen de la potestad de parar y cachear en los países anglosajones.}

\begin{tabular}{|l|l|}
\hline \multicolumn{2}{|l|}{ Leyes comunes Reino Unido } \\
\hline $\begin{array}{l}\text { Sección } 23 \text { - Misuse of Drugs Act } \\
1971\end{array}$ & $\begin{array}{l}\text { Búsqueda de drogas. } \\
\text { Requisito de sospecha razonable individualizada. }\end{array}$ \\
\hline Sección 47 - Firearms Act 1968 & $\begin{array}{l}\text { Búsqueda de armas prohibidas. } \\
\text { Requisito de sospecha razonable individualizada. }\end{array}$ \\
\hline $\begin{array}{l}\text { Sección } 60 \text { - Criminal Justice and } \\
\text { Public Order Act 1994 }\end{array}$ & $\begin{array}{l}\text { Uso intensificado para la prevención e } \\
\text { investigación de actos violentos colectivos en una } \\
\text { zona delimitada. } \\
\text { Sin requisito de sospecha razonable } \\
\text { individualizada. }\end{array}$ \\
\hline
\end{tabular}

8 La traducción al español no permite diferenciar entre «search» $\mathrm{y}$ «frisk», el último implica un cacheo superficial, menos intrusivo (ver por ejemplo: https:// en.oxforddictionaries.com/definition/frisk), aunque para la práctica policial la diferencia entre «stop and search» $\mathrm{y}$ "stop and frisk» es mínima.

9 De ahí que esta práctica también reciba el nombre de «Terry stops».

10 Por ejemplo, permitiendo a los agentes parar a un «sospechoso habitual» (United States v. Hensley, US SUPREME COURT, 1985) e incluyendo el lugar donde se encuentra la persona como uno de los criterios que pueden fundar la sospecha (Illinois v. Wardlow, US SUPREME COURT, 2000). 


\begin{tabular}{|c|c|}
\hline \multicolumn{2}{|l|}{ Inglaterra y Gales } \\
\hline $\begin{array}{l}\text { Sección } 1 \text { - Police and Criminal } \\
\text { Evidence Act } 1984\end{array}$ & $\begin{array}{l}\text { Uso generalizado para la búsqueda de objetos } \\
\text { prohibidos, peligrosos o relacionados con algún } \\
\text { delito. } \\
\text { Requisito de sospecha razonable individualizada. }\end{array}$ \\
\hline $\begin{array}{l}\text { Sección } 163 \text { - Road Traffic Act } \\
1988\end{array}$ & $\begin{array}{l}\text { Uso en tráfico para la prevención o investigación } \\
\text { de delitos cometidos por conductores. } \\
\text { Requisito de sospecha razonable individualizada. }\end{array}$ \\
\hline \multicolumn{2}{|l|}{ Escocia } \\
\hline $\begin{array}{l}\text { Sección } 21 \text { - Criminal Law Act } \\
1995\end{array}$ & $\begin{array}{l}\text { Búsqueda objetos prohibidos en eventos } \\
\text { deportivos. } \\
\text { Requisito de sospecha razonable individualizada. }\end{array}$ \\
\hline $\begin{array}{l}\text { Sección 48(1) - Criminal Law Act } \\
1995\end{array}$ & $\begin{array}{l}\text { Búsqueda de armas prohibidas. } \\
\text { Requisito de sospecha razonable individualizada. }\end{array}$ \\
\hline $\begin{array}{l}\text { Sección } 50 \text { - Criminal Law Act } \\
1995\end{array}$ & $\begin{array}{l}\text { Búsqueda de objetos afilados. } \\
\text { Requisito de sospecha razonable individualizada. }\end{array}$ \\
\hline $\begin{array}{l}\text { Sección } 60 \text { (1) - Civic } \\
\text { Government Act } 1982\end{array}$ & $\begin{array}{l}\text { Búsqueda de objetos robados. } \\
\text { Requisito de sospecha razonable individualizada. }\end{array}$ \\
\hline \multicolumn{2}{|l|}{ Irlanda del Norte } \\
\hline $\begin{array}{l}\text { Sección } 3 \text { - Police and Criminal } \\
\text { Evidence (NI) Order } 1989\end{array}$ & $\begin{array}{l}\text { Uso generalizado para la búsqueda de objetos } \\
\text { prohibidos, peligrosos o relacionados con algún } \\
\text { delito. } \\
\text { Requisito de sospecha razonable individualizada. }\end{array}$ \\
\hline \multicolumn{2}{|l|}{ Estados Unidos } \\
\hline $\begin{array}{l}\text { Caso Terry v. Ohio de } 1968 \\
\text { Caso Adams v. Williams de } 1972 \\
\text { Caso United States v. Hensley de } \\
1985 \\
\text { Caso Illinois v. Wardlow de } 2000\end{array}$ & $\begin{array}{l}\text { Prevención e investigación de delitos (parada) y } \\
\text { búsqueda de drogas o armas (cacheo). } \\
\text { Requisito de sospecha razonable individualizada } \\
\text { para la parada y, posteriormente, para el cacheo. }\end{array}$ \\
\hline
\end{tabular}




\section{El modelo europeo continental: el control de identidad $^{11}$}

En el modelo europeo continental la parada policial está concebida principalmente para proceder a la identificación de personas en la vía pública y una de las características que diferencia a este modelo del anterior es que aquí se prevé, directa o indirectamente, que la parada policial sirva también para realizar controles de inmigración. Este modelo está presente en la mayoría de países de Europa continental, así como en países de Europa del este e incluso países latinoamericanos. A continuación se presentará la regulación en algunos países europeos y en Chile.

En Francia el artículo 78 del Code de procédure pénale de 1959 regula las identificaciones policiales de forma general. La policía puede identificar a alguien si sospecha que esta persona ha participado en la comisión de un delito. También, mediante autorización de fiscalía, puede llevar a cabo identificaciones en una zona delimitada para prevenir amenazas contra el orden público o la seguridad personal. Por otro lado, la policía también puede llevar a cabo identificaciones en supuestos más concretos, como el control de la migración o en el marco de la lucha anti-terrorista. Respecto al primer supuesto, en base al artículo L611 del Code de l'Entrée et du Séjour des Étrangers et du Droit d'Asile de 2005, la policía puede requerir a una persona que se identifique para comprobar su situación administrativa respecto a la condición de extranjería, sin que esta demanda deba estar basada en una sospecha individualizada. Mientras que el artículo 23 de la Loi de Sécurité Quotidienne de 2001 introdujo la posibilidad a los agentes de policía de realizar paradas a personas y vehículos con el objetivo de detectar indicios de participación en actividades terroristas, sin necesidad de fundamentar esta parada en indicios concretos.

En Alemania las identificaciones están reguladas en la sección 163b del Strafprozessordnung de $1987^{12}$. Este poder puede ser utilizado con fines indagatorios o preventivos ante la sospecha de que una persona haya o vaya a cometer un delito en el futuro. Además, como en otros contextos mencionados como Francia, los mandos policiales pueden delimitar una zona de alto riesgo (donde ha habido o se prevé que ocurran hechos violentos) y en este área llevar a cabo identificaciones de manera altamente discrecional, sin necesidad de justificar individualmente cada identificación.

11 La selección de países incluidos está realizada en base a la disponibilidad de información (investigaciones y legislación) en lengua inglesa o española.

12 Sin embargo, los Länder pueden tener especificidades al respecto en sus respectivas disposiciones legales. 
En Hungría existen diferentes supuestos que permiten a la policía parar e identificar ciudadanos, regulados en el artículo 29 de la évi XXXIV - törvény a Rendörségröl de 1994. En primer lugar, este artículo establece que la policía puede parar e identificar a cualquier persona «cuya identidad personal requiera ser determinada» con los objetivos de protección del orden público, la seguridad pública, la prevención de la delincuencia, la detección de delitos, para establecer el estatus residencial de una persona y la protección de los derechos de la persona a identificar. En segundo lugar, un agente de policía puede parar e identificar a una persona en el ámbito del control de tráfico sin necesidad de justificar esta parada en una sospecha o comportamiento ilegal observado. En tercer lugar, existe el llamado «control intensivo» que se da cuando un jefe de una unidad de policía determina un lugar y un tiempo específico durante el cual se pueden llevar a cabo identificaciones, sin tener que evaluar criterios individuales, con el objetivo de detener a un sospechoso de cometer un delito o hacer frente a una amenaza a la seguridad pública.

Tal y como se ha indicado supra, el modelo continental también se sigue en algunos países latinoamericanos. Por ejemplo, en Chile el artículo 85 del Código Procesal Penal de 2000 dota a la los Carabineros y a la Policía de Investigaciones de la facultad de parar a personas en la calle y pedirles que revelen su identidad. Esto puede llevarse a cabo cuando exista algún indicio para pensar que estas personas quieren ocultar su identidad (porque van encapuchados por ejemplo), han participado en la comisión de un acto delictivo o tienen información respecto hechos delictivos. El artículo 12 del mismo código establece la posibilidad de que se lleven a cabo identificaciones de forma preventiva sin ningún tipo de requisito.

En la siguiente tabla (Tabla 2) puede verse un resumen de las disposiciones que regulan los controles de identidad bajo el modelo europeo continental de los países mencionados.

\section{Tabla 2. Resumen de los artículos que regulan las identificaciones policiales en Francia, Alemania, Hungría y Chile.}

\begin{tabular}{|c|c|}
\hline \multicolumn{2}{|l|}{ Francia } \\
\hline $\begin{array}{l}\text { Artículo } 78 \text { - Code de procédure } \\
\text { pénale } 1959\end{array}$ & $\begin{array}{l}\text { a) Investigación de delitos. } \\
\text { Requisito de existencia de indicios de la comisión } \\
\text { de un delito. } \\
\text { b) Uso intensificado para la prevención e } \\
\text { investigación de actos violentos colectivos en una } \\
\text { zona delimitada. } \\
\text { Sin requisitos de existencia de indicios } \\
\text { individualizados de comisión de un delito. }\end{array}$ \\
\hline
\end{tabular}




\begin{tabular}{|c|c|}
\hline \multicolumn{2}{|l|}{ Francia } \\
\hline $\begin{array}{l}\text { Artículo L611 - Code de l'Entrée } \\
\text { et du Séjour des Étrangers et du } \\
\text { Droit d'Asile } 2005\end{array}$ & $\begin{array}{l}\text { Búsqueda de personas en situación } \\
\text { administrativa irregular. } \\
\text { Sin requisitos de existencia de indicios } \\
\text { individualizados. }\end{array}$ \\
\hline $\begin{array}{l}\text { Artículo } 23 \text { - Loi de Sécurité } \\
\text { Quotidienne } 2001\end{array}$ & $\begin{array}{l}\text { Investigación de actos terroristas. } \\
\text { Sin requisitos de existencia de indicios } \\
\text { individualizados de comisión de un delito. }\end{array}$ \\
\hline \multicolumn{2}{|l|}{ Alemania } \\
\hline $\begin{array}{l}\text { Sección 163b - } \\
\text { Strafprozessordnung } 1987\end{array}$ & $\begin{array}{l}\text { a) Prevención e investigación de delitos. } \\
\text { Requisito de existencia de indicios de la comisión } \\
\text { de un delito o de la posibilidad de que ocurra en } \\
\text { el futuro. } \\
\text { b) Uso intensificado para la prevención e } \\
\text { investigación de actos violentos colectivos en una } \\
\text { zona delimitada. } \\
\text { Sin requisitos de existencia de indicios } \\
\text { individualizados de comisión de un delito. }\end{array}$ \\
\hline \multicolumn{2}{|l|}{ Hungría } \\
\hline $\begin{array}{l}\text { Artículo } 29 \text { - évi XXXIV, törvény a } \\
\text { Rend凶rségr®l } 1994\end{array}$ & $\begin{array}{l}\text { a) Necesidad de identificar a una persona en una } \\
\text { investigación policial. } \\
\text { Sin requisitos de existencia de indicios } \\
\text { individualizados de comisión de un delito. } \\
\text { b) Uso intensificado para la prevención e } \\
\text { investigación de actos violentos colectivos en una } \\
\text { zona delimitada. } \\
\text { Sin requisitos de existencia de indicios } \\
\text { individualizados de comisión de un delito. } \\
\text { c) Necesidad de identificar de forma } \\
\text { suplementaria a cualquier persona con la que } \\
\text { intervenga antes de o al iniciar cualquier otra } \\
\text { actuación. } \\
\text { Sin requisitos de existencia de indicios } \\
\text { individualizados de comisión de un delito. }\end{array}$ \\
\hline \multicolumn{2}{|l|}{ Chile } \\
\hline $\begin{array}{l}\text { Artículo } 85 \text { - Código Procesal } \\
\text { Penal } 2000\end{array}$ & $\begin{array}{l}\text { Investigación de delitos. } \\
\text { Requisito de existencia de indicios de la comisión } \\
\text { de un delito. }\end{array}$ \\
\hline
\end{tabular}




\begin{tabular}{|l|l|}
\hline \multicolumn{2}{|l|}{ Chile } \\
\hline $\begin{array}{l}\text { Artículo } 12 \text { - Código Procesal } \\
\text { Penal } 2000\end{array}$ & $\begin{array}{l}\text { Prevención de delitos. } \\
\text { Sin requisitos de existencia de indicios } \\
\text { individualizados de comisión de un delito. }\end{array}$ \\
\hline
\end{tabular}

\section{La regulación de la identificación policial en España}

Antes de 1992 no existía ningún precepto legal que regulara las paradas policiales en España. Sin embargo, estas ocurrían bajo el nombre de "controles policiales superficiales» (que incluían identificaciones y cacheos) (PORTILLA, 1996).

A partir de la Ley Orgánica 1/1992, de 21 de febrero, sobre Protección de la Seguridad Ciudadana ${ }^{13}$ se regulaban dos supuestos en los que un agente de policía podía proceder a la identificación de una persona. El artículo 20 de dicha ley disponía que los agentes de policía podían requerir la identificación de las personas en la vía pública o semipública en el marco de sus funciones de indagación y prevención de delitos e infracciones administrativas. Mientras que el artículo 19.2 establecía que se podían establecer dispositivos masivos de identificación con el objetivo de descubrir y detener a los implicados en delitos generadores de grave alarma social.

$\mathrm{Al}$ respecto de esta nueva figura de identificación surgió un debate jurídico sobre si se podía considerar la parada de una persona en la vía pública, con el objetivo de identificarla, una forma de privación de libertad. Según la jurisprudencia constitucional ${ }^{14}$ constituyen acciones que no afectan a la libertad de movimiento siempre que sean momentáneas, proporcionadas, necesarias e instrumentales para labores de prevención o indagación de infracciones penales. Sin embargo, sobre el supuesto del artículo 20.2, el traslado a dependencias policiales para practicar una identificación que no ha sido posible en la vía pública, el Tribunal Constitucional, en su sentencia STC 341/1993, lo calificó como modalidad de privación de libertad. Pero consideró que era una modalidad diferente a la detención y que, por lo tanto, la persona afectada no se encontraba protegida por las mismas garantías que una persona detenida.

13 Actualmente, derogada por la Ley Orgánica 4/2015, de 30 de marzo, de protección de la seguridad ciudadana.

14 SSTC 107/1985, 22/1988 y 341/1993. Puede verse un análisis en mayor detalle en VARELA y RAMÍREZ (2010). 
En 2015, y después de introducir cambios en el anteproyecto de 2013 y el proyecto de $2014^{15}$, entró en vigor la Ley Orgánica 4/2015, de 30 de marzo, de protección de la seguridad ciudadana (a partir de ahora LOPSC). Esta ley presenta algunos cambios respecto a las identificaciones y contiene varias tipologías de estas.

El artículo 16 de la LOPSC regula las identificaciones individuales y establece que «en el cumplimiento de sus funciones de indagación y prevención delictiva, así como para la sanción de infracciones penales y administrativas, los agentes de las Fuerzas y Cuerpos de Seguridad podrán requerir la identificación de personas». A partir de aquí se establecen dos supuestos en los que los agentes de policía pueden practicar una identificación según el primer apartado del artículo.

El primero de estos supuestos es «cuando existan indicios de que han podido participar en la comisión de una infracción» (identificaciones indagatorias). Es decir, los agentes podrán identificar a una persona cuando tengan indicios, una base objetiva y no una mera sospecha subjetiva, de que ha participado en un delito o una infracción administrativa para denunciarla ante el órgano correspondiente (judicial o administrativo) en funciones de investigación criminal o de policía administrativa.

El segundo supuesto que se contempla es «cuando, en atención a las circunstancias concurrentes, se considere razonablemente necesario que acrediten su identidad para prevenir la comisión de un delito». Es decir, cuando los agentes lo consideren necesario para prevenir un delito (no así en el caso de infracciones administrativas).

Una novedad respecto a la anterior regulación que se introduce en el artículo 16.1, fruto de las polémicas sobre el uso del perfil étnico en las identificaciones ${ }^{16}$ (DE LA SERNA, 2017), es que se establece que la identificación deberá respetar

15 Desde que el Partido Popular presentó el anteproyecto en 2013 esta ley ha estado envuelta en polémica. Ha contado con la oposición, además de la mayoría de grupos parlamentarios, de varios actores relevantes como el Consejo General del Poder Judicial o el Comité de Derechos Humanos de la ONU (BILBAO, 2015). Popularmente es conocida como «ley mordaza», ya que se concibe como un intento de frenar la protesta fruto de la crisis económica de 2008 y sus consecuencias políticas limitando los derechos de reunión y manifestación y aumentando la «inmunidad» policial (BILBAO, 2015; JUECES PARA LA DEMOCRACIA, 2014; MAQUEDA, 2015).

16 Además de por organizaciones como AMNISTÍA INTERNACIONAL ESPAÑA (2011) e instituciones nacionales como el DEFENSOR DEL PUEBLO (2013), el uso del perfil étnico en las identificaciones policiales ha sido denunciado por organismos internacionales, como por ejemplo el CERD en un informe de 2016 (CERD, 2016), el Relator Especial sobre las formas contemporáneas de racismo, discriminación racial, xenofobia y formas conexas de intolerancia (NACIONES UNIDAS, 2013) y por la ECRI en su informe de 2011 (ECRI, 2011). Este último informe derivó en que en 2013 el Comité de Ministros del Consejo de Europa instara a España a erradicar esta práctica (DE LA SERNA, 2017). 
«los principios de proporcionalidad, igualdad de trato y no discriminación por razón de nacimiento, nacionalidad, origen racial o étnico, sexo, religión o creencias, edad, discapacidad, orientación o identidad sexual, opinión o cualquier otra condición o circunstancia personal o social» ${ }^{17}$

Ante esos dos supuestos un agente de policía podrá requerir a una persona que se identifique en la vía pública o semi-pública. El apartado segundo del artículo 16 de la LOPSC dispone que

«los agentes, para impedir la comisión de un delito o al objeto de sancionar una infracción, podrán requerir a quienes no pudieran ser identificados a que les acompañen a las dependencias policiales más próximas en las que se disponga de los medios adecuados para la práctica de esta diligencia, a los solos efectos de su identificación y por el tiempo estrictamente necesario, que en ningún caso podrá superar las seis horas. La persona a la que se solicite que se identifique será informada de modo inmediato y comprensible de las razones de dicha solicitud, así como, en su caso, del requerimiento para que acompañe a los agentes a las dependencias policiales.»

Si el agente de policía no puede practicar la identificación en la vía pública, por razón de que el afectado se niega a identificarse o por motivos técnicos (no se cuenta con los medios telemáticos para comprobar su identidad), puede «pedir» ${ }^{18}$ a la persona a identificar que le acompañe a las dependencias policiales más cercanas, con el único objetivo de identificarle y solamente durante el tiempo necesario para ello (con un límite máximo de 6 horas), solamente en situaciones en que sea necesaria la identificación para impedir la comisión de un delito o para denunciar una infracción administrativa ${ }^{19}$.

17 Para DE LA SERNA (2017), aunque insuficiente, esto supone superar la STC 13/2001. En esta sentencia el Tribunal Constitucional estableció que estaba justificado en base a criterios estadísticos que la policía requiriera la identificación de personas no blancas por su mayor probabilidad de ser extranjeras.

18 Uno de los problemas que plantea este supuesto es el de que no queda suficientemente claro el grado de obligatoriedad que tiene una persona ante el requerimiento de la autoridad policial para que le «acompañe» a dependencias policiales. El hecho de que existan posibles consecuencias punitivas ante la resistencia o negativa a identificare (actualmente, apartado 5 del artículo 16), parece dar a entender que la persona no tiene muchas opciones de acción ante la petición (MAQUEDA, 2015; VARELA y RAMÍREZ, 2010). De hecho el Tribunal Constitucional en su STC 341/1993, respecto a la anterior regulación, estableció que no es posible hablar de libre voluntad en este supuesto ante la expectativa de consecuencias negativas.

19 Según VECINO (2008), basándose en jurisprudencia previa, no cabe el traslado a dependencias policiales por motivo de la comisión de una infracción administrativa que no afecte a la seguridad (por ejemplo, de una ordenanza municipal de limpieza o de cuestiones de extranjería). La inobservancia de estas motivaciones para el traslado, por ejemplo llevando a alguien a comisaría por el simple hecho de no portar documento identificativo, puede hacer que los agentes incurran en un delito de detención ilegal. Esto ya supuso una condena a dos agentes de una policía local por este delito en la STS 1007/2002 de 27 de mayo (RÍOS et al., 2015). 
El apartado tercero del artículo 16 de la LOPSC requiere que las identificaciones practicadas en dependencias policiales queden registradas en un libro-registro al cual solo podrán tener acceso las autoridades judiciales competentes y del cual se deberá remitir extracto de manera mensual al Ministerio Fiscal. La Instrucción 7/2015 de la Secretaria de Estado de Seguridad relativa a la práctica de la diligencia de identificación, los registros corporales externos y actuaciones con menores, previstos en la Ley Orgánica 4/2015, de 30 de marzo, de protección de la seguridad ciudadana (a partir de ahora Instrucción 7/2015), establece el procedimiento de confección del libro-registro y los datos que deben constar, que son: la identificación de los agentes mediante su número de carnet profesional o tarjeta de identificación personal y su unidad de adscripción (tanto de los agentes que trasladan a la persona no identificada a las dependencias policiales como de todos aquellos que participen en la realización de la identificación); el motivo de la identificación; las diligencias realizadas de forma detallada; y observaciones derivadas de «circunstancias extraordinarias» y de manera obligatoria el hecho de que «la persona ha sido informada de modo inmediato, comprensible y adaptado a sus necesidades de las razones de la identificación». Esta información introducida en el libro registro deberá ser cancelada de oficio a los tres años.

A la persona a la que se le practica la diligencia de identificación en dependencias policiales se le deberá entregar «un volante acreditativo del tiempo de permanencia en ellas, la causa y la identidad de los agentes actuantes» (artículo 16.4 de la LOPSC). En la Instrucción 7/2015 puede encontrarse un modelo de volante donde se debe hacer constar, entre otros aspectos: nombre y apellidos de la persona identificada, documento identificativo, fecha de nacimiento, identidad de los agentes que han participado, motivo del traslado a dependencias policiales (negativa a identificarse o imposibilidad de identificar en el lugar de los hechos), el objetivo de la identificación (prevenir la comisión de un delito o sancionar una infracción), y el tiempo de duración de la diligencia. Este volante además se deberá adjuntar al atestado si la identificación da lugar a otras diligencias.

La persona que se resista o se niegue a identificarse en los términos que regula el artículo 16 puede enfrentarse a diferentes consecuencias legales, como señala su apartado quinto. Por un lado, como resultado de la modificación legal, la propia LOPSC prevé sanciones administrativas para estas personas. El artículo 36.6 de la LOPSC califica la negativa a identificarse o la alegación de datos falsos o inexactos como una infracción grave. A este tipo de infracciones le corresponden multas de 601 a 10.400 euros (grado mínimo), de 10.401 a 20.200 euros (grado medio) o de 20.201 a 30.000 euros (grado máximo) (artículo 39.1 de la LOPSC de 2015), además de las posibles sanciones accesorias del apartado segundo del artículo 39 de la LOPSC. Todo ello cuando la negativa o resistencia no sea constitutiva de un delito de resistencia o desobediencia a agente de la autoridad, que puede conllevar penas de hasta 3 años de prisión (artículos 550, 551, 553 y 556 del Código Penal). 
Por último, el artículo 17.2 de la LOPSC prevé otros supuestos en los que los agentes de policía pueden llevar a cabo identificaciones. En concreto este apartado establece que

«Para la prevención de delitos de especial gravedad o generadores de alarma social, así como para el descubrimiento y detención de quienes hubieran participado en su comisión y proceder a la recogida de los instrumentos, efectos o pruebas, se podrán establecer controles en las vías, lugares o establecimientos públicos, siempre que resulte indispensable proceder a la identificación de personas que se encuentren en ellos, al registro de vehículos o al control superficial de efectos personales.»

En este caso se puede hablar de identificaciones colectivas dirigidas a la prevención e/o investigación de delitos «concretos»: delitos de especial gravedad o generadores de alarma social ${ }^{20}$.

Pese a que la LOPSC no lo dispone expresamente ni en su artículo 16 ni en el 17, las identificaciones policiales se utilizan frecuentemente para controles de extranjería (DE LA SERNA, 2017; MARTÍNEZ y SÁNCHEZ, 2013). Esto se ve habilitado por el hecho de que no tener permiso de residencia es una infracción administrativa grave en base al artículo 53.1. de la Ley Orgánica 4/2000, de 11 de enero, sobre derechos y libertades de los extranjeros en España y su integración social.

\section{Tabla 3. Resumen de los artículos que regulan las identificaciones policiales en España.}

\begin{tabular}{|c|c|}
\hline \multicolumn{2}{|l|}{ España } \\
\hline Artículo 16 - LOPSC 2015 & $\begin{array}{l}\text { a) Investigación de delitos e infracciones } \\
\text { administrativas. } \\
\text { Requisito de existencia de indicios de la comisión } \\
\text { de un delito. } \\
\text { b) Prevención de delitos. } \\
\text { Requisito de «necesidad razonable». }\end{array}$ \\
\hline
\end{tabular}

20 Así como en el caso del artículo 16 de la LOPSC, sobre las identificaciones individuales, se han introducido, en general, cambios «garantistas» con respecto al artículo 20 de la LOPSC de 1992 (límite de seis horas en las identificaciones en dependencias policiales o la obligación de informar de las razones de la identificación), en el caso del artículo 17 de la LOPSC de 2015, referido a las identificaciones colectivas, parece ocurrir lo opuesto. Además del cambio de «un hecho delictivo causante de grave alarma social» a "delitos de especial gravedad o generadores de alarma social», donde no parece haber mucho avance ya que siguen siendo conceptos igualmente indeterminados, el cambio más significativo es la desaparición de la obligación de informar de forma inmediata al Ministerio Fiscal de esta práctica (BILBAO, 2015; DE LA SERNA, 2017; MAQUEDA, 2015). 


\begin{tabular}{|l|l|}
\hline \multicolumn{2}{|l|}{ España } \\
\hline Artículo 17.2 - LOPSC 2015 & $\begin{array}{l}\text { Uso intensificado para la prevención e } \\
\text { investigación de delitos de extrema gravedad y } \\
\text { generadores de alarma social. } \\
\text { Sin requisitos de existencia de indicios } \\
\text { individualizados de comisión de un delito. }\end{array}$ \\
\hline
\end{tabular}

\section{La dificultad de regular y monitorear las paradas policiales $^{21}$}

Pese a las diferencias en la regulación de las paradas policiales, la investigación criminológica sobre su práctica parece indicar que existen dificultades en la limitación y control de esta potestad policial que son similares en todos los contextos (BRADFORD y LOADER, 2016; DE LA SERNA, 2017; DELSOL y SHINER, 2006; LENNON y MURRAY, 2018; MEARES, 2014; OPEN SOCIETY JUSTICE INITIATIVE, 2009; RÍOS et al., 2015).

Los principales controles que se imponen sobre la práctica de las paradas policiales son a nivel legal. Existen razones para creer en la posibilidad de someter la actuación policial a control legal efectivo. El marco legal establece los límites donde la práctica de las paradas policiales se da y la regulación forma parte activa de su práctica, puesto que la policía cuando actúa toma decisiones legales y los incidentes que afronta acaban definiéndose en términos legales (DIXON, 1997; QUINTON, 2011). Sin embargo, en general, las regulaciones dotan de un margen amplio de discrecionalidad a la policía para decidir a quién parar (BOWLING y WEBER, 2011; DE LA SERNA, 2017; DELSOL y SHINER, 2006; MAILLARD, HUNOLD, ROCHÉ y OBERWITTLER, 2018; OPEN SOCIETY JUSTICE INITIATIVE, 2009). Y cuando se limita esa discrecionalidad, por ejemplo con requisitos como el de sospecha razonable, existen ejemplos de cómo los agentes logran sortearlos (ASWORTH Y ZEDNER, 2014; BRADFORD y LOADER, 2016; DELSOL y SHINER, 2006; DIXON, 1997; QUINTON, 2011).

21 Aunque también se exponen ejemplos de países del modelo europeo continental (y españoles), la mayor parte de la evidencia expuesta en este apartado hace referencia al contexto anglosajón. Esto es debido, como ya se ha ido exponiendo a lo largo del artículo, a que allí existe mayor investigación al respecto (BOWLING y MARKS, 2015; REINER, 2010), seguramente como consecuencia de la mayor accesibilidad a datos policiales (OPEN SOCIETY JUSTICE INITIATIVE, 2009). Algunos autores han tratado la falta de transparencia en la actividad policial en España (ver, por ejemplo, DE LA SERNA, 2017) y en Europa continental en general (OPEN SOCIETY JUSTICE INITIATIVE, 2009). La falta de datos no solo supone un problema para la investigación académica sino que supone una menor rendición de cuentas (LENNON, y MURRAY, 2018). 
En el modelo anglosajón uno de los requisitos legales clave es el elemento de sospecha razonable. Este requisito debería limitar el poder de parar y cachear haciendo que los agentes solo puedan realizar paradas cuando existen hechos o información objetiva sobre una persona que apunta a su implicación en un hecho delictivo (ASWORTH y ZEDNER, 2014; BRADFORD y LOADER, 2016). También debería permitir un control retrospectivo y la posibilidad de reparación en caso de abuso (BOWLING y MARKS, 2015). Sin embargo, como se ha visto, en la práctica los policías hacen una interpretación amplia de esta limitación y saben cómo sortearla, por ejemplo, encontrando una justificación que encaje retrospectivamente o utilizando motivaciones más débiles de las que deberían justificar el uso de este poder (en el límite de lo requerido por la regulación o la jurisprudencia ${ }^{22}$ ) (ASWORTH y ZEDNER, 2014; DIXON, 1997; REINER, 2010).

Otro de los requisitos que se imponen en algunas legislaciones es el hecho de tener que justificar la parada y registrar esta motivación en un formulario (esto ocurre sobre todo, de nuevo, en el modelo anglosajón). Cuando en algunos casos se han revisado las justificaciones utilizadas por agentes de policía en estos formularios se ha podido observar los problemas que existen con la motivación del uso de esta potestad. Por ejemplo, la Fiscalía del Estado de Nueva York realizó una investigación en 1999 sobre los formularios que los policías deben cumplimentar cuando realizan una parada policial y concluyó que el 15\% no estaban suficientemente justificados y que la constitucionalidad de 1 de cada 3 paradas era cuestionable (SPITZER, 1999 citado en GELLER y FAGAN, 2010). Por otro lado, en Reino Unido, en una investigación similar, se observó que el $27 \%$ de los formularios no contenían motivos razonables suficientes para realizar una parada policial (HMIC, 2013).

Pese a que la regulación permite, a priori, un control preventivo de la actuación policial, un control integral necesita de la capacidad de que las instituciones y el público en general puedan hacer un monitoreo retrospectivo. Esto es difícil en el caso de las paradas policiales, puesto que suelen darse en contextos de baja visibilidad, donde normalmente solo tienen conocimiento de la práctica el agente (o agentes) que la lleva a cabo y la persona parada. Por lo tanto, si no existe la obligación y la voluntad de que se registre cada parada es muy probable que no quede constancia de algunas de ellas y que las decisiones que toman los agentes queden impunes a los mecanismos de rendición de cuentas (BRADFORD y LOADER,

22 En el estudio de FAGAN y GELLER (2015), donde se utilizó datos de aproximadamente 4,7 millones de formularios de paradas de la policía de Nueva York de 2004 a 2012, se observa como los motivos a priori más en concordancia con la regulación (como por ejemplo observar directamente una compra-venta de drogas o ver a alguien con un objeto sospechoso) son los que menos utilizan los agentes para justificar una parada policial. 
2016; DELSOL y SHINER, 2006; MAILLARD et al., 2018). Por ello uno de los aspectos clave para controlar la actividad de paradas es la recogida de información y la publicación de datos. Sin embargo, en muchos países no existe la obligación de publicación de datos que permitan monitorear esta actividad policial (BOWLING y MARKS, 2015; BOWLING y WEBER, 2011; DE LA SERNA, 2017; IRARRÁZABAL, 2015; MAILLARD et al., 2018; OPEN SOCIETY JUSTICE INITIATIVE, 2009). Incluso en los países donde sí existe la obligación de publicar los datos sobre paradas, como Reino Unido y Estados Unidos, algunas investigaciones han encontrado una disonancia entre las paradas observadas y las paradas registradas en los datos oficiales (DIXON, 1997; GELMAN et al., 2007).

A pesar del pesimismo que se puede derivar de los aspectos mencionados, en la última década existen ejemplos de cómo la limitación legal y el control retrospectivo pueden ser efectivos en algunos casos y pueden llevar a reducir el uso discrecional de las paradas policiales, así como las disparidades raciales que ocurren en la práctica de estas, como parece mostrar el periodo posterior a la sentencia del caso Floyd et al $v$ the City of New York (US DISTRICT COURT FOR THE SOUTHERN DISTRICT OF NEW YORK, 2013) en Nueva York (MACDONALD y BRAGA, 2018; MANSKI y NAGIN, 2017), y, en cierta manera, los cambios en la práctica policial ocurridos en Reino Unido 23 después de los casos que pusieron el foco de la atención pública sobre las paradas (LENNON y MURRAY, 2018; QUINTON, 2011). Sin embargo, algunos autores defienden que más que la regulación legal y el control judicial en sí mismos, lo que parece ser clave en estos casos es el escrutinio público que ha envuelto a estas prácticas a raíz de las polémicas generadas (BRADFORD y LOADER, 2016; GELMAN et al., 2007; LENNON y MURRAY, 2018).

\section{Conclusiones}

Las distintas regulaciones de las paradas policiales comparten una serie de similitudes, como la justificación de esta potestad en el control de la delincuencia o que se prevean supuestos de excepcionalidad, aunque también se pueden destacar diferencias notables como los criterios que deben generar sospecha policial o el hecho de utilizar esta potestad como un mecanismo de control de la inmigración irregular.

La principal similitud entre los modelos es que en ambos las paradas policiales se justifican como un medio de control de la delincuencia, ya sea para investigarla como para prevenirla, aunque después se prevea

23 Aunque en el caso de este país, pese a las mejoras como que cada vez se registre y se justifique mejor su uso, y la reducción muy pronunciada en las paradas y cacheos en términos generales, algunos problemas como las disparidades raciales se mantienen (HMICFRS, 2017). 
legalmente una utilización más amplia en el modelo continental europeo. Otra similitud es que a pesar de tener distintos objetivos inmediatos (requerir la identidad o cachear) en ambos casos las paradas policiales están consideradas como el recurso legal más inmediato con el que cuenta la policía para desarrollar sus funciones. Por último, en ambos casos se habilita un uso extraordinario mediante la posibilidad de que mandos policiales establezcan una zona determinada, donde han ocurrido episodios de violencia graves o se prevé que ocurran, donde los agentes de policía pueden llevar a cabo paradas policiales por un tiempo determinado, sin necesidad de fundamentarlas en indicios concretos o en una sospecha razonable individualizada.

La principal diferencia es que en la regulación de los países anglosajones existe el requisito de sospecha razonable para que el agente de policía pueda iniciar una parada y este requisito ha sido desarrollado en las normativas y por la jurisprudencia, lo que parece que ha hecho que los motivos de las paradas policiales sean objeto de un mayor escrutinio en estos países. Esto puede ser explicado por su orientación más investigativo-criminal, donde se tiene más presente la posibilidad de que la parada policial sea el inicio de un procedimiento penal. Este criterio de sospecha razonable se ha intentado incluir en el marco europeo a través del Tribunal Europeo de Derechos Humanos. En el caso Gusinskiy v. Russia (TEDH, 2004) el tribunal estableció que para que una parada esté legalmente justificada «la sospecha debe basarse en motivos razonables, constituyendo una salvaguardia importante frente a los controles y detenciones arbitrarios. El hecho de que la sospecha se desprenda de la buena fe no es suficiente. La expresión sospecha razonable significa la existencia de hechos o informaciones que satisfarían a un observador imparcial sobre la posibilidad de que la persona en cuestión haya cometido una infracción». Por último, otra diferencia relevante, es que en el modelo continental, por su mayor orientación (al menos explícita) hacía el mantenimiento del orden, las paradas policiales se reconocen también como una herramienta de control de la inmigración irregular.

Pese a las similitudes y diferencias en la regulación, en la práctica se ha podido observar las limitaciones legales en el control de la actividad de paradas policiales en ambos modelos, debido en buena medida al amplio espacio de discrecionalidad que dotan las diferentes legislaciones a los agentes de policía y los espacios de baja visibilidad donde ocurren estas paradas.

Más allá de las limitaciones propias del control legal en cualquier ámbito, y especialmente en el policial, la investigación criminológica ha resaltado una limitación muy relevante respecto a las paradas policiales. Buena parte de la literatura al respecto ha señalado que las paradas policiales tienen otros fines distintos a los establecidos en las diferentes legislaciones. No son, o al menos no principalmente, una herramienta para el control de la delincuencia sino una herramienta de clasificación 
social. Mediante esta potestad lo que se busca es mantener a ciertos colectivos, aquellos que en la literatura angloparlante se enmarcan en el concepto police property ${ }^{24}$, bajo un control intensivo y constante puesto que representan una amenaza para el orden social que la policía defiende (BOWLING y MARKS, 2015; BOWLING y WEBER, 2011; BRADFORD, 2017; BRADFORD y LOADER, 2016; DELSOL y SHINER, 2015).

En vista de las problemáticas mencionadas (dificultad de control, uso del perfil étnico, fines no autorizados explícitamente, etc.) se podría proponer simplemente la derogación de esta potestad policial. Sin embargo, esto puede tener efectos contraproducentes (como un aumento en las detenciones) (BRADFORD y LOADER, 2016). Por lo tanto, lo que se propone es un aumento de la monitorización de esta actividad policial, teniendo en cuenta que un control efectivo requiere de una conjunción de regulación, supervisión judicial y, sobre todo, escrutinio público.

\section{Referencias}

\section{Bibliográficas}

Amnistía Internacional España. (2011). Parad el racismo, no a las personas: perfiles raciales y control de la inmigración en España. Recuperado de https://amnistiainternacional.org/publicaciones/147-parad-el-racismo-no-a-las-pers-onas-perfiles-raciales-ycontrol-de-la-inmigracion-en-espana.html [última consulta 18 de junio de 2019]

Asworth, A. y Zedner, L. (2014). Prevention, Policing and Criminal Procedure. En Preventive justice (pp. 51-73). Oxford: Oxford University Press.

BiLbaO, J. M. (2015). La llamada ley mordaza: la Ley Orgánica 4/2015 de protección de la seguridad ciudadana. Teoría y Realidad Constitucional, (36), 217-260.

Bowling, B. y MARKs, E. (2015). Towards a Transnational and Comparative Approach. En R. DELSOL y M. SHINER (Eds.), Stop and Search: The Anatomy of a Police Power (pp. 170-192). Basingstoke: Palgrave Macmillan UK.

Bowling, B. y WeBer, L. (2011). Stop and search in global context: an overview. Policing and Society, 21(4), 480-488.

24 Este concepto hace referencia, por ejemplo, a los jóvenes varones de clase trabajadora que pasan mucho tiempo en la calle, a ciertas minorías étnicas y personas racializadas, a personas migradas de determinados países, y en general a todas aquellas personas que pertenecen a grupos desaventajados en términos políticos o económicos (REINER, 2010). 
BRADFORD, B. (2015). Unintended consequences. En R. DELSOL y M. SHINER (Eds.), Stop and Search: The Anatomy of a Police Power (pp. 102-122). London: Palgrave Macmillan UK.

- (2017). Stop and Search and Police Legitimacy. Abingdon: Routledge.

BRADFORD, B. y LOADER, I. (2016). Police, crime and order: the case of Stop and Search. En B. BRADFORD, B. JAUREGUI, I. LOADER y J. STEINBERG (Eds.), The SAGE Handbook of Global Policing (pp. 241-266). London: SAGE.

CERD. (2016). Observaciones finales sobre los informes periódicos vigésimo primero, vigésimo segundo y vigésimo tercero de España (CERD/C/ESP/ CO/21-23). Recuperado de http://tbinternet.ohchr.org/Treaties/CERD/ SharedDocuments/ESP/INT_CERD_COC_ESP_23910_S.pdf [última consulta 18 de junio de 2019]

Defensor Del Pueblo. (2013). Informe Anual a las Cortes Generales. Recuperado de https://www.defensordelpueblo.es/wpcontent/ uploads/2015/05/2013_Informe_A-nual_Vol_I_Informe_2013.pdf [última consulta 18 de junio de 2019]

De La Serna, C. (2017). Control de la inmigración en la vía pública: cuando el color de la piel es la frontera. En A. LÓPEZ-SALA y D. GODENAU (Eds.), Estados de contención, estados de detención: el control de la inmigración irregular en España (pp. 75-96). Barcelona: Anthropos Editorial.

Delsol, R. y ShINER, M. (2006). Regulating stop and search: a challenge for police and community relations in England and Wales. Critical Criminology, 14(3), 241-263.

- (2015). Stop and Search: the anatomy of police power. Basingstoke: Palgrave Macmillian UK.

Demichele, M. \& Janoski, T. (2010). A Regime Theory Approach to CrossNational Incarceration Rate Variation: Three Worlds of Western Punishment, 1960-2002. Recuperado de http://papers.ssrn.com/sol3/papers. cfm?abstract_id=1535265 [última consulta 8 de abril de 2020]

Dixon, D. (1997). Law in Policing: Legal Regulation and Police Practices. Oxford: Clarendon Press.

ECRI. (2011). Cuarto Informe Sobre España. Recuperado de https://www. idhc.org/arxius/noticies/1418377635-20110208_InformeECRI.pdf [última consulta 18 de junio de 2019]

FAGAN, J. y Geller, A. (2015). Following the Script: Narratives of Suspicion in Terry Stops in Street Policing. The University of Chicago Law Review, 82(1), 51-88.

Geller, A. y Fagan, J. (2010). Pot as Pretext: Marijuana, Race, and the New Disorder in New York City Street Policing. Journal of Empirical Legal Studies, 7(4), 591-633. 
Gelman, A., Fagan, J. y Kiss, A. (2007). An Analysis of the New York City Police Department's «Stop-and-Frisk» Policy in the Context of Claims of Racial Bias. Journal of the American Statistical Association, 102(479), 813-823.

Hміс. (2013). Stop and search powers: are the police using them effectively and fairly? Recuperado de https://www.justiceinspectorates.gov.uk/ hmicfrs/media/stop-and-search-powers-20130709.pdf [última consulta 18 de junio de 2019]

HMicfrs. (2017). PEEL: Police legitimacy 2017: a national overview. Recuperado de https://www.justiceinspectorates.gov.uk/hmicfrs/wpcontent/uploads/peel-police-legitimacy-2017-1.pdf [última consulta 18 de junio de 2019]

IRARRÁZABAL, P. (2015). Igualdad en las calles en Chile: el caso del control de identidad. Política Criminal, 10(19), 234-265.

Jueces Para La Democracia. (2014). Orden público y restricción de las libertades: análisis de la reforma de la legislación penal y administrativa desde la perspectiva de la protección de los derechos fundamentales. Recuperado de https://laicismo.org/data/docs/archivo_1365.pdf [última consulta 18 de junio de 2019]

LenNon, G. y MurRay, K. (2018). Under-regulated and unaccountable? Explaining variation in stop and search rates in Scotland, England and Wales. Policing and Society, 28(2), 157-174.

Macdonald, J. y Braga, A. A. (2018). Did Post-Floyd et al. Reforms Reduce Racial Disparities in NYPD Stop, Question, and Frisk Practices? An Exploratory Analysis Using External and Internal Benchmarks. Justice Quarterly, 1-30.

Maillard, J. De, Hunold, D., Roché, S. y Oberwittler, D. (2018). Different styles of policing: discretionary power in street controls by the public police in France and Germany. Policing and Society, 28(2), 175-188.

Manski, C. F. y Nagin, D. S. (2017). Assessing benefits, costs, and disparate racial impacts of confrontational proactive policing. Proceedings of the National Academy of Sciences, 114(35), 9308-9313.

Maqueda, M. L. (2015). La criminalización del espacio público: el imparable ascenso de las «clases peligrosas.» Revista Electrónica de Ciencia Penal y Criminología, (17-12), 1-56.

Martínez, M. y Sánchez, J. M. (2013). Controles de identidad, detenciones y uso del perfil étnico en la persecución penal y castigo del inmigrante «sin papeles»: ilegalidad e inconstitucionalidad de determinadas prácticas policiales. En F. J. ÁLVAREZ GARCÍA, M. Á. COBOS GÓMEZ DE LINARES, P. GÓMEZ PAVÓN, A. MANJÓN-CABEZA OLMEDA y A. MARTÍNEZ GUERRA (Eds.), Libro homenaje al prof. Luis Rodíguez Ramos (pp. 1025-1054). Valencia: Tirant lo Blanch. 
Mawby, R. I. (2008). Models of policing. En T. Newburn (Ed.), Handbook of Policing (2nd ed., pp. 17-46). Cullompton: Willan Publishing.

Meares, T. L. (2014). The Law and Social Science of Stop and Frisk. Annual Review of Law and Social Science, (10), 335-352.

Ministerio Del Interior. (2016). Anuario Estadístico del Ministerio del Interior 2015. Recuperado de http://www.interior.gob.es/documents/642317/1204854/Anuario-Estadistico- 2015.pdf/03be89e1-dd3847a2-9ce8-ccdd74659741 [última consulta 19 de junio de 2019]

Murray, K. (2014b). Stop and Search in Scotland: an evaluation of a police practice (SCCJR Report 01/2014). Recuperado de https:/www.sccjr. ac.uk/wp-content/uploads/2014/01/St-op_and_Search_in_Scotland1. pdf [última consulta 18 de junio de 2019]

Murray, K. y Harkin, D. (2017). Policing in Cool and Hot Climates: Legitimacy, Power and the Rise and Fall of Mass Stop and Search in Scotland. British Journal of Criminology, 57(4), 885-905.

NACIONES UNIDAS. (2013). Informe del Relator Especial sobre las formas contemporáneas de racismo, discriminación racial, xenofobia y formas conexas de intolerancia, Mutuma Ruteere, presentado en el $23^{\circ}$ periodo de sesiones Consejo de Derechos Humanos, el 6 de junio de 2013, A/ $H R C$. Recuperado de https:/www.acnur.org/fileadmin/Documentos/ BDL/2015/9831.p-df [última consulta 18 de junio de 2019]

Open Society Justice Initiative. (2009). Adressing Ethnic Profiling by Police: A Report on the Strategies for Effective Police Stop and Search Project. Recuperado de https://www.opensocietyfoundations.org/sites/ default/files/profiling_20090511.pdf [última consulta 19 de junio de 2019]

Portilla, G. (1996). Identificaciones, cacheos, controles policiales y otros entretenimientos de la libertad: una réplica a las tesis legitimadoras del retroceso histórico en materia de libertad y seguridad personal. Jueces Para La Democracia, (26), 12-21.

Quinton, P. (2011). The formation of suspicions: police stop and search practices in England and Wales. Policing and Society, 21(4), 357-368.

REINER, R. (2010). The politics of the police ( $4^{\mathrm{a}}$ ed.). New York: Oxford University Press.

Ríos, J., Segovia, J. L. y EtXebarria, X. (2015). Manual para la defensa de los derechos y las libertades ante la intervención de la policía. Madrid: Universidad Pontificia Comillas.

Topping, J. y Schubotz, D. (2018). The 'usual suspects'? Young people's experiences of police stop and search powers in Northern Ireland. Research Update, (120), 1-6.

United Kingdom Government. (2015). Police powers and procedures England and Wales year ending 31 March 2015: data tables. Recupera- 
do de https://www.gov.uk/government/statistics/police-powers-andprocedures-england-and-wales-year-ending-31-march-2015-datatables [última consulta 8 de abril de 2020]

Varela, X. y Ramírez, J. L. (2010). Doce tesis en materia de detención policial preprocesal. Revista Catalana de Seguretat Pública, 22, 207-230.

Vecino, M. (2008). Análisis de la identificación. Recuperado de http:// www.policiacanaria.com/sites/default/files/identificacion_revista_ guardia_civil_03-2008.pdf [última consulta 19 de junio de 2019]

\section{Normativas}

Chile. (2000). Código Procesal Penal. Disponible en https://www.leychile. $\mathrm{cl} /$ Navegar?idNorma $=176595$

Deutschland. (1987). Strafprozessordnung. Disponible en https://www. gesetze-im-internet.de/englisch_stpo/index.html

France. (1959). Code de procédure pénale. Disponible en https://www. legifrance.gouv.fr/affichCode.do?cidTexte=LEGITEXT000006071154

France. (2001). Loi de Sécurité Quotidienne. Disponible en https://www. legifrance.gouv.fr/affichTexte.do?cidTexte=JORFTEXT000000222052

France. (2005). Code de l'Entrée et du Séjour des Étrangers et du Droit d'Asile. Disponible en https://www.legifrance.gouv.fr/affichCode.do?c idTexte=LEGITEXT000006070158

Home Office. (2014). Police and Criminal Evidence Act 1984 (PACE) - Code A. Disponible en https://assets.publishing.service.gov.uk/ government/uploads/system/uploads/attachment_data/file/384122/ PaceCodeAWeb.pdf

Instrucción 7/2015 de la Secretaria de Estado de Seguridad relativa a la práctica de la diligencia de identificación, los registros corporales externos y actuaciones con menores, previstos en la Ley Orgánica 4/2015, de 30 de marzo, de protección de la seguridad ciudadana

Ley Orgánica 1/1992, de 21 de febrero, sobre Protección de la Seguridad Ciudadana [disposición derogada]. Jefatura del Estado, BOE, núm. 46, de 22 de febrero de 1992, pág. 6209.

Ley Orgánica 10/1995, de 23 de noviembre, del Código Penal. Jefatura del Estado, BOE, núm. 281, de 24 de noviembre de 1995, pág. 33987.

Ley Orgánica 4/2000, de 11 de enero, sobre derechos y libertades de los extranjeros en España y su integración social. Jefatura del Estado, BOE, núm. 10, de 12 de enero de 2000, pág. 1139.

Ley Orgánica 4/2015, de 30 de marzo, de protección de la seguridad ciudadana. Jefatura del Estado, BOE, núm. 77, de 31 de marzo de 2015, pág. 27216. 


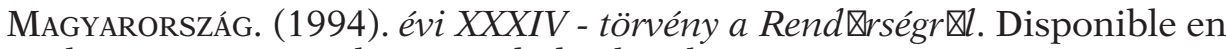
https://net.jogtar.hu/jogszabaly?docid=99400034.TV

United Kingdom. (1968). Firearms Act 1968 (c. 27). Disponible en https:// www.legislation.gov.uk/ukpga/1968/27/contents

- (1971). Misuse of drugs Act 1968 (c. 38). Disponible en https://www. legislation.gov.uk/ukpga/1971/38/contents

- (1982). Civic Government Act 1982 (c. 45). Disponible en https://www. legislation.gov.uk/ukpga/1982/45/contents

- (1984). Police and Criminal Evidence Act 1984 (c. 60). Disponible en https://www.legislation.gov.uk/ukpga/1984/60/contents

— (1988). Road Traffic Act 1988 (c. 52). Disponible en https://www.legislation.gov.uk/ukpga/1988/52/contents

- (1989). The Police and Criminal Evidence (Northern Ireland) Order 1989. Disponible en http://www.legislation.gov.uk/nisi/1989/1341/ contents

— (1994). Criminal Justice and Public Order Act 1994 (c. 33). Disponible en https://www.legislation.gov.uk/ukpga/1994/33/contents

- (1995). Criminal Law Act 1995 (c. 39). Disponible en https:/www.legislation.gov.uk/ukpga/1995/39/contents

\section{Jurisprudencia}

Tribunal Constitucional. (1985). Sentencia 107/1985, de 7 de octubre.

- (1988). Sentencia 22/1988, de 18 de febrero.

- (1993). Sentencia 341/1993, de 18 de noviembre.

- (2001). Sentencia 13/2001, de 29 de enero.

Tribunal Europeo De Derechos Humanos. (2004). Gusinski v. Russia [Application no. 70276/01].

- (2010). Gillan and Quinton v. United Kingdom [Application no. 4158/05].

Tribunal Supremo. (2002). Sentencia 1007/2002, de 27 de mayo.

Us District Court For The Southern District Of New York (2013). Floyd et al $v$ the City of New York [959 F. Supp. 2d 540].

Us Supreme Court. (1968). John W. Terry v. State of Ohio [392 U.S. 1].

- (1972). Frederick E. Adams v. Robert Williams [407 U.S. 143]

- (1985). United States v. Thomas J. Hensley [469 U.S. 221]

- (2000). Illinois, Petitionerv. William aka Sam Wardlow [528 U.S. 119] 
